\title{
Looking under the bonnet of conservation conflicts: can neuroscience help?
}

\author{
Özgün Emre $\operatorname{Can}^{1}$ D $\cdot$ David W. Macdonald ${ }^{1}$
}

Received: 21 September 2017 / Revised: 21 December 2017 / Accepted: 24 January 2018 /

Published online: 31 January 2018

(C) The Author(s) 2018. This article is an open access publication

\begin{abstract}
Neuroscience - a branch of biology seemingly distant from nature/wildlife conservation is revolutionised by the ability to visualise the brain activity of humans. Using positron emission tomography (PET), functional magnetic resonance imaging (fMRI) and magnetoencephalograhy (MEG), neuroscience is revealing how humans are wired in ways that have bearing on any problem that involves values; and nature/wildlife conservation is surely one of those. Understanding how the human brain represents and processes morality and sacred values, and responds to conflicts could shed a powerful light on nature/wildlife conservation tactics. Conservation polices typically involve utilitarian considerations. However, research shows that conservation policies based solely on utilitarian considerations are likely to fail as the neurological process of rights and wrongs grates against the process of cost and benefits.
\end{abstract}

Keywords Conflict resolution · Human brain - Human carnivore conflict · Human wildlife conflict $\cdot$ Neuroscience $\cdot$ Wildlife conservation

\section{Introduction}

Might conservation be better nudged forward if its practitioners understood the technicalities of what happens 'under the bonnets' of the people who comprise its problems and solutions? The question arises because remarkable advances in neuroscience-a branch of biology seemingly distant from conservation-are revealing how humans are wired in

Communicated by David Hawksworth.

This article belongs to the Topical Collection: Biodiversity appreciation and engagement.

Özgün Emre Can

emre.can@zoo.ox.ac.uk

1 Wildlife Conservation Research Unit, Department of Zoology, The Recanati-Kaplan Centre, University of Oxford, Tubney House, Tubney, Oxon OX13 5QL, UK 
ways that have bearing on any problem that involves values, and conservation is surely one of those. The confluence of ideas that prompts this sideways look at conservation and neuroscience is this: on the one hand, and while the bedrock of conservation is evidence (Macdonald et al. 2007), conservation decision-making goes beyond evidence, through values to judgment and thus to politics (Macdonald and Willis 2013). As Vucetich and Macdonald (2017) argue in the context conserving carnivores, the prospects for success will be heavily affected by the intrinsic value attached to these animals. On the other hand, neuroscience has recently exposed particular neurological processes when people encounter topics involving values and morality. Hence the inter-disciplinary confluence and the question of whether neuroscience might help conservationists understand, or at least diagnose, how its stakeholders respond to given issues.

As with so many leaps forward, the question can be posed only because technological breakthroughs have created new possibilities. Fifty years ago, as Passingham (2016) observes, speculating on what happens in people's brains might have been considered unscientific. Today, neuroscience (the study of the structure and function of the nervous system and brain) is revolutionised by the ability to visualise the brain activity of humans, for example by positron emission tomography (PET), functional magnetic resonance imaging (fMRI), and magnetoencephalography (MEG). It is now possible to record the activity of single neurons (Mormann et al. 2008; Passingham 2016).

\section{Human brain, morality and conservation}

The confluence between conservation and neuroscience that has caught our attention concerns morality, and morality is surely a result of evolutionary forces (Moll et al. 2005). Morality, in brief, is about making choices in our daily lives in a resource scarce world (Tetlock 2003; Moll et al. 2005). Understanding morality has been the eternal preoccupation of scholarship in both the Humanities (anthropology, law, philosophy to name but a few) and Natural Science (such as psychology and evolutionary biology), so both intellectual spheres will be enriched by the neuroscientists' discovery that human brains are wired for morality (Moll et al. 2005). Functional neuroimaging and brain lesion analysis have begun to show how it works (Koenigs et al. 2007; Moll and Oliveira-Souza 2007). Moral phenomena start to be seen as an amalgam of contextual social knowledge (represented as event knowledge in the prefrontal cortex), social semantic knowledge (stored in the anterior and posterior temporal cortex) and motivational and basic emotional states (dependent on cortical-limbic circuits) (Moll et al. 2005). The trolley car dilemma (see Thomson 1985; Foot 1978), itself the source of library-fuls of trolleyological insight, is now becoming a gold mine for neuroscience (Greene et al. 2009). It seems that for the human brain some problems (such as saving four lives instead of one) are merely a matter of maths (Shenhav and Greene 2014) and activate brain regions involved in logical problems (Eagleman 2016). Drawing on an analogy from ancient traditions, these actuarial problems activate the rider but not the elephant in the rider-and-elephant complex (Haidt 2006). (We can think of the rider as the prefrontal cortex where conscious reasoning occurs and the rider can reason, talk and explain things, whereas the elephant is the amygdala or everything else apart from the prefrontal cortex (Haidt 2006; Vaisy 2008). However, under the scenario when the dilemma involves pushing an innocent bystander off a bridge to save the lives of four, additional brain networks spring into action: those involved in emotion (Eagleman 2016), 
at which point the elephant trumpets in agitation, and takes control without consulting the rider.

So, what of conservation? Well, almost all conservation problems extend beyond evidence into ethics, and thus call on intellectual and emotional territory beyond clinical evidence. Of course, this is completely obvious, and the ethics and politics of conservation are vibrant arenas. What has not hitherto been obvious is that it is possible to see these distinctions in the functioning brain, and it becomes clear that both elephant and rider influence the journey. While breakthroughs for tackling conservation in the next 50 years will doubtless involve unimagined technology (Can and Macdonald 2017), it is even more sure that ethical dilemmas will come into ever greater prominence [see Global Biodiversity Outlook 4 (Secretariat of the Convention on Biological Diversity 2014); Now for the long term (Oxford Martin School 2013; Macdonald et al. 2016, 2017)], and a revolution in how we value nature will be as important as one in how we study it (Vucetich and Macdonald 2017), with an urgent need for fundamental principles (Vucetich et al. in prep).

\section{Human brain, sacred values and conservation}

Although evidence crucially underpins judgement and although some economists might say everything has an implicit or explicit price (Tetlock 2003), value is, as is often attributed to Oscar Wilde, very different to price, and values can be sacrosanct (Tetlock 2003; Berns et al. 2012). For example, for many people, fundamental beliefs and values such as love, honour, national and ethnic identities are practically sacred in nature (Tetlock 2003; Berns et al. 2012).

Indeed, values are doubtless a greater contributor to many human conflicts than are disputes over evidence (Ginges et al. 2007), and in this context it is noteworthy that humanwildlife conflicts in conservation are often styled as human-human conflicts (Marshall et al. 2007; Redpath et al. 2013). None of this is surprising, but it highlights that any evidence, as might emerge from neuroscience, regarding the way people define and respond to values could be helpful when they are the nub of conservation issues. Research shows that when individuals hold some values, certain commitments and relations to be sacred, they may not reason instrumentally, and thus they fail to make trade-offs (Tetlock 2003). Under these circumstances, established penalties or offered motives in policy programmes have no traction on their choices (Tetlock 2003; Ginges et al. 2007; Berns et al. 2012). The elephant overrides the rider. Therefore, understanding how the human brain represents and processes sacred values could shed a revealing light on conservation tactics.

Consider the use of the skins of endangered wild animals in fashion and in religious ceremonies; these might, at first blush, seem similar problems for conservation. Studies using functional magnetic resonance imaging (fMRI), a useful tool to measure brain regions associated with decision-making in humans, indicate that deontological (rights and wrongs) and utilitarian (cost and benefits) processing are associated with different brain regions (Berns et al. 2012). Indeed, people use neural systems associated with evaluating rights and wrongs (left and right temporoparietal junction) and semantic retrieval (ventrolateral prefrontal cortex) but not brain networks associated with utility when they process statements about sacred values (Berns et al. 2012). When sacred values are contradicted, activity in the amygdala, the part of the brain that is involved in fear and other emotional processes (Phelps and LeDoux 2005), increases. This is indicative of negative emotion (Berns et al. 2012), and one which causes the metaphorical elephant to react. Importantly, 
the overall assessment of the action in decision-making is supplied by the amygdala (Shenhav and Greene 2014). It seems likely, therefore, that discussion about the use of skins of endangered mammals will have different neurological characteristics depending on whether the use is for fashion or religion. Consequently, disagreements over skins in religious ceremonies, but not those in fashion, may trigger conflict or violence (Berns et al. 2012).

Dickman et al. (2015) took the position that "conservation biologists have a duty to promote science, even if that requires implicitly or explicitly criticising a cultural practice". They were surely mindful that exercising that duty would require far greater circumspection if the practice in question was closer to the sacred than the secular, and this obvious distinction is now confirmed neurologically. Insofar as the future of conservation is a quest for alignment of human and conservation imperatives (Macdonald et al. 2007), neuroscience may soon offer evidence for a taxonomy of reactions that would assist that quest.

\section{Conclusion}

Like economic, foreign and military policies (Berns et al. 2012), conservation polices typically involve utilitarian considerations but typically also involve judgments that reflect values. Neuroscience provides hard evidence that the human species makes choices through two conflicting processes (rights and wrongs versus cost and benefits) each doubtless with its selective advantages (Eagleman 2016; Greene 2015). As in any other sector, when sacred values are at stake, conservation policies based solely on utilitarian considerations are likely to fail as the neurological process of rights and wrongs grates against the process of cost and benefits. How these processes are reconciled 'under the bonnet' of the human mind has not yet been discovered by neuroscience-but when it is, conservation could be an important beneficiary.

Open Access This article is distributed under the terms of the Creative Commons Attribution 4.0 International License (http://creativecommons.org/licenses/by/4.0/), which permits unrestricted use, distribution, and reproduction in any medium, provided you give appropriate credit to the original author(s) and the source, provide a link to the Creative Commons license, and indicate if changes were made.

\section{References}

Berns GS, Bell E, Capra CM, Prietula MJ, Moore S, Anderson B, Ginges J, Atran S (2012) The price of your soul: neural evidence for the non-utilitarian representation of sacred values. Philos Trans R Soc Lond B Biol Sci 367(1589):754-762

Can ÖE, Macdonald DW (2017) To protect everything, please click here: does a revolution in data collection guarantee one in conservation? Anim Conserv 20:1-2. https://doi.org/10.1111/acv.12285

Dickman A, Johnson PJ, van Kesteren F, Macdonald DW (2015) The moral basis for conservation: how is it affected by culture? Front Ecol Environ 13:325-331. https://doi.org/10.1890/140056

Eagleman D (2016) The brain. The story of you. Canongate Books, Edingburg

Foot P (1978) The problem of abortion and the doctrine of double effect. In: Foot P (ed) Virtues and Vices. Blackwell, Oxford

Ginges J, Atran S, Medin D, Shikaki K (2007) Sacred bounds on rational resolution of violent political conflict. Proc Natl Acad Sci U S A 104(18):7357-7360

Greene J (2015) Moral Tribes. Atlantic Books, London

Greene Joshua D, Cushman Fiery A, Stewart Lisa E, Lowenberg Kelly, Nystrom Leigh E, Cohen Jonathan D (2009) Pushing moral buttons: the interaction between personal force and intention in moral judgment. Cognition 111(3):364-371 
Haidt J (2006) The happiness hypothesis. Arrow Books, London

Koenigs M, Young L, Adolphs R, Tranel D, Cushman F, Hauser M, Damasio A (2007) Damage to the prefrontal cortex increases utilitarian moral judgements. Nature 446(7138):908-911. https://doi. org/10.1038/nature05631

Macdonald DW, Willis K (2013) Elephants in the room: tough choices for a maturing discipline. In: Macdonald D, Willis K (eds) Key topics in conservation biology, vol 2. Wiley, Hoboken, pp 468-494

Macdonald DW, Collins NM, Wrangham R (2007) Principles, practice and priorities: the quest for alignment. In: Macdonald D, Service K (eds) Key topics in conservation biology. Blackwell Publishing Ltd, Oxford, pp 271-290

Macdonald DW, Johnson PJ, Loveridge AJ, Burnham D, Dickman AJ (2016) Conservation or the moral high ground: siding with bentham or kant. Conserv Lett 9:307-308. https://doi.org/10.1111/conl.12254

Macdonald DW, Loveridge AJ, Dickman A, Johnson PJ, Jacobsen KS, Du Preez B (2017) Lions, trophy hunting and beyond: knowledge gaps and why they matter. Mam Rev. https://doi.org/10.1111/ mam. 12096

Marshall K, White R, Fischer A (2007) Conflicts between humans over wildlife management: on the diversity of stakeholder attitudes and implications for conflict management. Biodivers Conserv 16:3129. https://doi.org/10.1007/s10531-007-9167-5

Moll J, de Oliveira-Souza R (2007) Moral judgments, emotions and the utilitarian brain. Trends Cognit Sci 11(8):319-321

Moll J, Zahn R, de Oliveira-Souza R, Krueger F, Grafman J (2005) Opinion: the neural basis of human moral cognition. Nat Rev Neurosci 6(10):799-809

Mormann F, Kornblith S, Quian Quiroga R, Kraskov A, Cerf M, Fried I, Koch C (2008) Latency and selectivity of single neurons indicate hierarchical processing in the human medial temporal lobe. J. Neurosci. 28(36):8865-8872. https://doi.org/10.1523/JNEUROSCI.1640-08.2008

Oxford Martin School (2013). Now for the long term: the report of the Oxford Martin Commission for Future Generations

Passingham R (2016) Cognitive neuroscience. Oxford University Press, New York, p 134

Phelps EA, LeDoux JE (2005) Contributions of the amygdala to emotion processing: from animal models to human behaviour. Neuron 48:175-187

Redpath Steve M et al (2013) Understanding and managing conservation conflicts. Trends Ecol Evol 28(2):100-109

Secretariat of the Convention on Biological Diversity (2014) Global biodiversity outlook 4: summary and conclusions. Secretariat of the Convention on Biological Diversity, Montréal, p 20

Shenhav A, Greene JD (2014) Integrative moral judgment: dissociating the roles of the amygdala and ventromedial prefrontal cortex. J Neurosci 34(13):4741-4749. https://doi.org/10.1523/JNEUR OSCI.3390-13.2014

Tetlock PE (2003) Thinking the unthinkable: sacred values and taboo cognitions. Trends Cognit Sci 7(7):320-324

Thomson JJ (1985) The trolley problem. Yale Law J 94(6):1395-1415

Vaisy S (2008) Socrates, skinner, and aristotle: three ways of thinking about culture in action. Sociol Forum 23(3):603-613

Vucetich JA, Macdonald WD (2017) Some essentials on coexisting with carnivores. Open Access Government. August Issue, pp. 216-217 